\title{
Mapping malaria risk using geographic information systems and remote sensing: The case of Bahir Dar City, Ethiopia
}

\author{
Amare Sewnet Minale, Kalkidan Alemu \\ Department of Geography and Environmental Studies, Bahir Dar University, Bahir Dar, Ethiopia
}

\begin{abstract}
The main objective of this study was to develop a malaria risk map for Bahir Dar City, Amhara, which is situated south of Lake Tana on the Ethiopian plateau. Rainfall, temperature, altitude, slope and land use/land cover (LULC), as well as proximity measures to lake, river and health facilities, were investigated using remote sensing and geographical information systems. The LULC variable was derived from a 2012 SPOT satellite image by supervised classification, while $30-\mathrm{m}$ spatial resolution measurements of altitude and slope came from the Shuttle Radar Topography Mission. Metrological data were collected from the National Meteorological Agency, Bahir Dar branch. These separate datasets, represented as layers in the computer, were combined using weighted, multi-criteria evaluations. The outcome shows that rainfall, temperature, slope, elevation, distance from the lake and distance from the river influenced the malaria hazard the study area by $35 \%, 15 \%, 10 \%, 7 \%, 5 \%$ and $3 \%$, respectively, resulting in a map showing five areas with different levels of malaria hazard: very high $(11.2 \%)$; high $(14.5 \%)$; moderate $(63.3 \%)$; low $(6 \%)$; and none $(5 \%)$. The malaria risk map, based on this hazard map plus additional information on proximity to health facilities and current LULC conditions, shows that Bahir Dar City has areas with very high (15\%); high (65\%); moderate $(8 \%)$; and low $(5 \%)$
\end{abstract}

Correspondence: Amare Sewnet Minale, Department of Geography and Environmental Studies, Bahir Dar University, Bahir Dar, Ethiopia. Tel.: +251.0583.20.60.68 - Fax: +251.0583.20.60.94.

E-mail: amare1974@gmail.com

Key words: Malaria; Hazard; GIS; Remote sensing; Risk computation model; Weighted multi criteria; Ethiopia.

Contributions: ASM contributed in reviewing and writing the introduction and analysis of the data. KA assisted in collecting data and performing the GIS analysis.

Conflict of interest: the authors declare no potential conflict of interest.

Funding: none.

Received for publication: 11 December 2017.

Revision received: 20 February 2018.

Accepted for publication: 5 March 2018.

CCopyright A.S. Minale and K. Alemu, 2018

Licensee PAGEPress, Italy

Geospatial Health 2018; 13:660

doi:10.4081/gh.2018.660

This article is distributed under the terms of the Creative Commons Attribution Noncommercial License (CC BY-NC 4.0) which permits any noncommercial use, distribution, and reproduction in any medium, provided the original author(s) and source are credited. levels of malaria risk, with only $2 \%$ of the land completely riskfree. Such risk maps are essential for planning, implementing, monitoring and evaluating disease control as well as for contemplating prevention and elimination of epidemiological hazards from endemic areas.

\section{Introduction}

Malaria is a vector-borne disease caused by infection of red blood cells with protozoan parasites of the genus Plasmodium, where the parasites enter the human body through the bite of an infected female blood-feeding, anopheline mosquito (Cooke et al., 2016). The most serious form of malaria is caused by Plasmodium falciparum which can be life-threatening. Due to the vector-dependent transmission of this disease, the environment plays an important role in determining its distribution and biodiversity (Guthmann et al., 2002).According to the latest World Malaria Report, close to half of the world's population is at risk of malaria, while there are 216 million actual cases and the World Health Organization (WHO) estimates that sub-Saharan Africa's share of the global malaria burden exceeds $90 \%$, including 91\% of deaths (WHO, 2017). Children under five, pregnant women and patients with infections, such as the human immunodeficiency virus (HIV), are at a particularly high risk of contracting malaria, which continues to kill a child every two minutes (WHO, 2017).

According to the Federal Ministry of Health (FMoH) in Ethiopia and individual researchers, three regions make up the large majority of the national malaria case load, i.e. Amhara in the North (29\%), Oromiya in the Centre South (13\%) and the Southern Nations, Nationalities, and Peoples' Region (SNNPR) in the Southeast (47\%) (Jima et al., 2010; FMoH, 2014). Three quarters of the country, with about $60 \%$ of the population, consist of malaria-prone areas resulting in repeated waves of malaria epidemics (FMoH, 2014). For instance, 3 million people were affected by malaria in 1958 and 150,000 died (Fontaine et al., 1961). Between 1986 and 1993, as many as 48 epidemic episodes were identified in various parts of the country, with a major epidemic in 1988 affecting the highlands (Abeku et al., 2003). A peak case load was reported in June 1997 but the trend declined in the consecutive months, after which the situation improved with the Ethiopian National Malaria Control Programme scaling up prevention and control activities, demonstrating that strong progress is possible through political will and committed partnerships (Jima et al., 2010).

Presence of malaria is strongly linked to environmental factors as they influence the abundance and survival of the mosquito vectors (Thomson et al., 1996; Abeku et al., 2003; Ceccato et al., 2005; Abiodun, et al., 2016). In warmer climates, the adult mosquito digests the blood meal faster and feeds more frequently, while the Plasmodium parasite completes the extrinsic incubation within its anopheline vector in a shorter time leading to increased transmission intensity as well as a higher proportion of infective mosquitoes 
(Aster, 2010). According to Brhanie (2016), both vector and parasite multiply slowly at cool temperatures with $15^{\circ} \mathrm{C}$ and $18^{\circ} \mathrm{C}$ being the minimum, depending on species, which precludes transmission in areas with ambient temperatures below these levels. Based on modelling, Mordecai et al. (2013) predict optimal transmission at $25^{\circ} \mathrm{C}$ with a strong decrease at temperatures above $28^{\circ} \mathrm{C}$.

The peak of malaria transmission follows the rainy season and its length is determined by the balance between precipitation and evaporation (Alemayehu, 2011; Amenu, 2014; FMoH, 2014). Rainfall, apart from supporting mosquito breeding, also affects malaria transmission through increased humidity which contributes to longevity of the adult vector, while altitudes above $2,500 \mathrm{~m}$ above the mean sea level (MSL) preclude transmission due to low temperatures (Aster, 2010; Alelign and Dejene, 2016). On the other hand, the Ethiopian lowlands below $1,500 \mathrm{~m}$ above MSL in the eastern and south-eastern parts of the country are prone to malaria infection, while the highlands, situated at 1500-2500 $\mathrm{m}$ above MSL (northern and central areas) experience malaria epidemics periodically depending on the climate (Abeku et al., 2003; Omukunda et al., 2013; Alelign and Dejene, 2016). Wind can be both negative and positive for the malaria cycle because strong winds decrease the mosquito biting frequency, while at the same time extending the length of its flight (Endo and Eltahir, 2018). Slope also has a variable impact, e.g., areas with high slopes are usually fragile, mountainous and unstable, while gentler elevation variations promote mosquito breeding through water retention (Clennon et al., 2010; Alemayehu, 2011). Land use/land cover (LULC) is associated with malaria transmission since vegetation provides a suitable environment for breeding with certain types of plant-cover playing an important role in determining vector abundance irrespective of a strong association with rainfall. It has, for example, been noted that rice irrigation schemes provide excellent breeding sites for Anopheles mosquitoes (Ceccato et al., 2005), while artificial irrigation aggravate control problems by increasing the number of aquatic larval habitats and extending the duration of the transmission season (Clennon et al., 2010; Ashenafi, 2013). The objective of this study was to assess and map malaria risk in the Bahir Dar area in the Amhara region of Ethiopia by an approach based on geographical information systems (GIS) with a remote sensing component. The former supplies the necessary infrastructure for identifying and combining environmental variables, while the latter continuously updates a broad range of environmental measurements and imagery making construction of up-todate, large-scale risk maps possible (Ceccato et al., 2005; Dessalegne et al., 2016). This methodology should provide improved prediction capabilities leading to efficient allocation of resources for malaria control and significantly enhance the ability of local communities, government and non-governmental organizations to conduct contingency planning for malaria prevention and elimination.

\section{Materials and Methods}

The study area is one of the major malaria risk areas in northern Ethiopia, with different organizations trying to tackle the malaria problem together with the FMoH. However, there is no detailed indication where the most vulnerable areas are situated, which makes risk mapping a priority.

\section{Study area}

The Bahir Dar administration in the north-western part of Ethiopia, with a total area close to $370 \mathrm{~km}^{2}$, is located $567 \mathrm{~km}$ from the capital Addis Ababa. It incorporates Bahir Dar City, the capital city of Amhara, located around the geographical coordinates of $11^{\circ} 35^{\prime} 34^{\prime \prime} \mathrm{N}$ and $37^{\circ} 23^{\prime} 03^{\prime \prime} \mathrm{E}$, and three small urban centres (satellite towns), namely Zegie, Tis Abay and Meshenti and their rural vicinities (Figure 1). The whole area is situated on the Ethiopian high plateau at 1,800 $\mathrm{m}$ above MSL. Figure 2 shows the general altitudes in Ethiopia and the most pronounced slopes in the South-Eastern

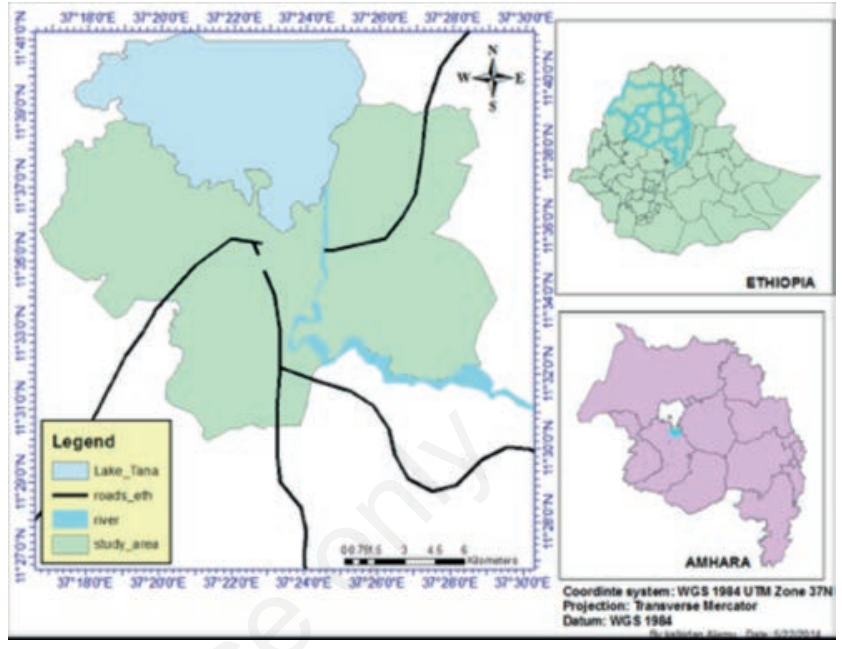

Figure 1. Map of the study area.

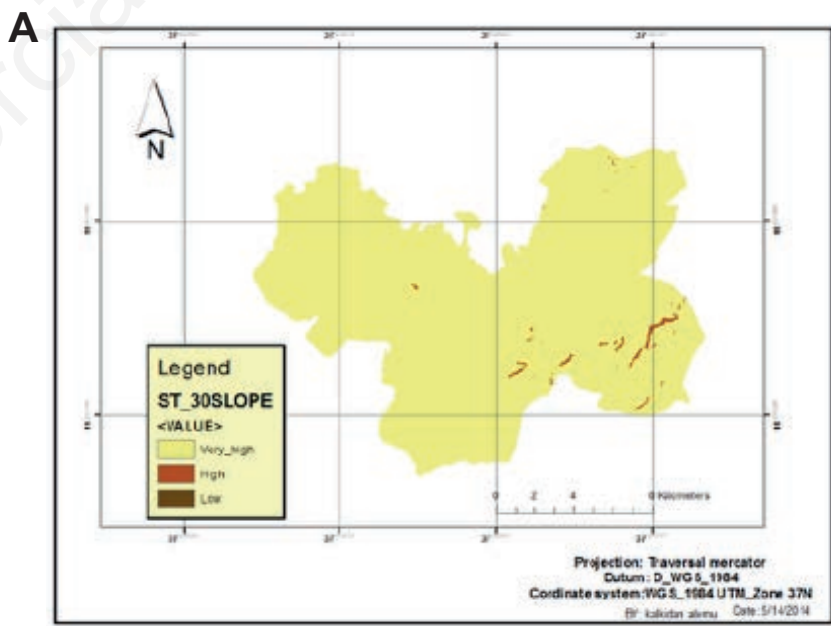

B

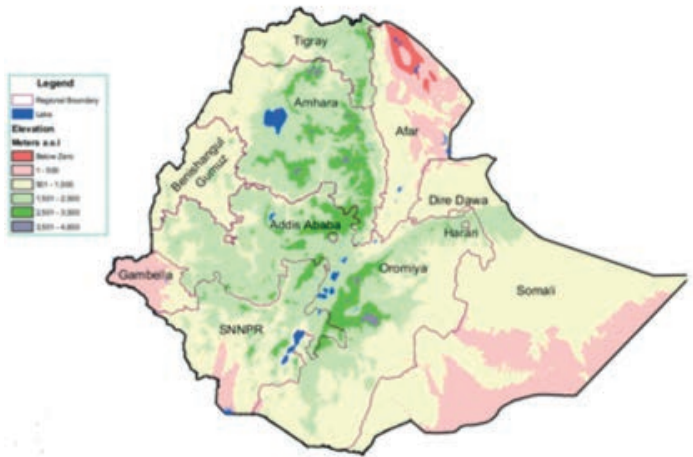

Figure 2. Terrain characteristics. A) Slopes in Bar Dar City; B) Altitudes in Ethiopia. 
part of the study area. There are significant seasonal variations of rainfall with around $60 \%$ of the annual rains in July and August, the highest temperatures in April (up to $30^{\circ} \mathrm{C}$ ), the lowest in July and August $\left(22-23^{\circ} \mathrm{C}\right)$ and wind speeds that can reach $1.8 \mathrm{~km}$. per sec (Amare and Kameswara, 2011). The study area is of highland type and characterized by one international waterway (Abbey River) and Lake Tana, the largest lake in Ethiopia $\left(>3,000 \mathrm{~km}^{2}\right)$, which is the source of the Blue Nile. Based on the Bahir Dar administration estimation in 2012, the total population of the city was about 277,566, with 135,441 males and 142,125 females. The area included a total of 40,893 households with an average of 4.47 persons per household distributed between 40,097 building units. The population density was 753 persons per $\mathrm{km}^{2}$.

\section{Data and approach}

We examined the relative effect on malaria transmission by temperature, rainfall, terrain (altitude and slope), proximity-related factors (distance from lake, river and health facilities) and LULC. The National Metrological Service Agency, Bahir Dar branch, provided the climatic data, while elevations and other topographic data, collected by the Shuttle Radar Topography Mission, were downloaded from the server of the United States Geological Survey (http://dds.cr.usgs.gov/srtm/). This information, together with shape files from the Ethiopian Mapping Agency, information from the FMoH $(2008,2014)$ and ancillary data obtained from field surveys, observations and focus group discussions with malaria control experts, allowed us to represent the extent of malaria prevalence over the study area.

The mean temperature and rainfall for each month for the latest
30 years were calculated by regression analysis carried out on Excel 2007. These values were utilized for surface interpolation of temperature and rainfall values over the study area creating layers of inverse distance weight using ArcGIS v.10.2 (ESRI, Redlands, CA, USA) applying the Spatial Analyst tool. For proximity-related malaria risk factors, such as distance from the lake, distance from the river and distance to health facilities, the same procedure was followed. Global positioning system (GPS) classification of ground control points, previously used to classify LULC in Bahir Dar, was used to identify distances and to pinpoint locations of the health facilities within the study area.

The values assigned for each variable was based on its estimated level of influence on malaria prevalence identified from prior research and discussions held with malaria experts working in the area. Importantly, influence levels vary from place to place so local conditions needed to be carefully considered before deciding on their relative influence. Since each risk factor has a separate degree of influence there was a need to determine the weight of each of the malaria risk factors chosen. Pair-wise comparison along with the Analytical Hierarchical Process (AHP) introduced by Saaty (1980) was used as a first step in the weighting process. This is a multi-criteria decision method that adopts hierarchical structures to first reduce complex decisions into a series of pair-wise comparisons and then produces the result as a synthesis. The AHP approach captures both subjective and objective aspects assisting judgments based on expert opinion. It also incorporates a technique for checking the consistency of the decision maker's evaluations, thus reducing the bias after decision-makers and experts had filled the comparison matrix. The weight computed for each factor are given in Tables 1 and 2 .

Table 1. Environmental factors and their comparative weight.

\begin{tabular}{|c|c|c|c|c|}
\hline Factor & Category & Vulnerability & Reference & Weight \\
\hline Annual rainfall & $\begin{array}{l}<800 \mathrm{~mm} \\
>800 \mathrm{~mm}\end{array}$ & $\begin{array}{l}\text { High } \\
\text { Very high }\end{array}$ & $\begin{array}{l}\text { Aster, } 2010 \\
\text { FMoH, } 2009\end{array}$ & $35 \%$ \\
\hline Ambient temperature $\left({ }^{\circ} \mathrm{C}\right)$ & $\begin{array}{l}<15 \\
20-23 \\
23-25 \\
25-27 \\
>30\end{array}$ & $\begin{array}{l}\text { None } \\
\text { Moderate } \\
\text { High } \\
\text { Very high } \\
\text { None }\end{array}$ & $\begin{array}{c}\text { Haque, } 2007 \\
\text { Mordecai et al., } 2013 \\
\text { Brhanie, } 2016\end{array}$ & $15 \%$ \\
\hline Slope $\left({ }^{\circ} \mathrm{C}\right)$ & $\begin{array}{l}0-7 \\
7-15 \\
15-20 \\
>20\end{array}$ & $\begin{array}{l}\text { Very high } \\
\text { High } \\
\text { Moderate } \\
\text { Low }\end{array}$ & Food and Agriculture Organization (FAO) & $10 \%$ \\
\hline Altitude (above MSL) & $\begin{array}{l}<2000 \mathrm{~m} \\
2,000-2,200 \mathrm{~m} \\
2,200-2,400 \mathrm{~m} \\
2,400-2500 \mathrm{~m} \\
>2,500 \mathrm{~m}\end{array}$ & $\begin{array}{l}\text { Very high } \\
\text { High } \\
\text { Moderate } \\
\text { Low } \\
\text { None }\end{array}$ & Meron, 2011 Alemayehu, 2011 & $7 \%$ \\
\hline Distance from water source (lake) & $\begin{array}{l}0-500 \mathrm{~m} \\
500-1,000 \mathrm{~m} \\
1,000-1,5000 \mathrm{~m} \\
1,500-2,000 \mathrm{~m} \\
>2,000 \mathrm{~m}\end{array}$ & $\begin{array}{l}\text { Very high } \\
\text { High } \\
\text { Moderate } \\
\text { Low } \\
\text { None }\end{array}$ & $\begin{array}{l}\text { Aster, } 2010 \\
\text { Arega, } 2009\end{array}$ & $5 \%$ \\
\hline Distance from water source (river) & $\begin{array}{l}0-500 \mathrm{~m} \\
500-1,000 \mathrm{~m} \\
1,000-1,500 \mathrm{~m} \\
1,500-2,000 \mathrm{~m} \\
>2,000 \mathrm{~m}\end{array}$ & $\begin{array}{l}\text { Very high } \\
\text { High } \\
\text { Moderate } \\
\text { Low } \\
\text { None }\end{array}$ & $\begin{array}{l}\text { Aster, } 2010 \\
\text { Arega, } 2009\end{array}$ & $3 \%$ \\
\hline
\end{tabular}




\section{Variables investigated}

Although anopheline mosquitoes can fly $10 \mathrm{~km}$, and be carried by wind much larger distances, dispersal studies have shown that $95 \%$ of these insects do not move further than around $2 \mathrm{~km}$ after breeding (Thomas et al., 2013). Since mosquitoes prefer humid breeding places, distance zones of $<500,500-1000,1000-1500$, 1500-2000 and $>2000 \mathrm{~m}$ from the lake and from the river were drawn up (Figure 3A and B) and ranked (Table 1). Counting from the water source, they were labelled as very high, high, moderate and low regarding malaria hazard with distances exceeding 2000 $\mathrm{m}$ counted as malaria-free in principle. With malaria prevention declining in line with the distance from a health facility, we ranked areas from 5-1 if situated within $1000 \mathrm{~m}$, between 1000-1500 m, between 1500-2000 m, between 2000-3000 $\mathrm{m}$ or further away than $3000 \mathrm{~m}$, respectively. (Figure 3C; Table 1).

For LULC data (Figure 4), we relied on the French high-resolution, Earth-observation system Satellite Pour l'Observation de la Terre (SPOT) (http://eoedu.belspo.be/en/satellites/spot.htm) based on supervised classification using the Earth Resource Dynamic Analysis System (ERDAS) (https://www.dataone.org/softwaretools/erdas-imagine). The SPOT imagery was selected for this study because of its high optical resolution and its link to ERDAS image processing software package that allows users to process geospatial and other imagery as well as vector data. The various land covers making up the LULC pattern were ranked based on the importance with regard to malaria as follows: water body fringes and wetlands (5), forest (4), settlements and agricultural land (3) and scrubland (2) where a higher figure infers more importance effect than a lower. GPS data were collected from the field and used as ground truth in the classification process.

When estimating the malaria risk, we emulated the calculations by Shook (1997) who originally applied his formula to express the risk with respect to natural disasters as follows:

$$
\mathrm{R}=\mathrm{H} \times \mathrm{E} \times \mathrm{V}
$$

where $\mathrm{R}$ is risk, $\mathrm{H}$ hazard, $\mathrm{E}$ the degree of exposure and $\mathrm{V}$ vulner-

Table 2. Base for the calculation of malaria risk based on hazard, distance to health facility and land cover.

\begin{tabular}{|c|c|c|c|}
\hline Factor & Weight & Category & Rank \\
\hline Hazard & $56 \%$ & $\begin{array}{l}\text { Very high } \\
\text { High } \\
\text { Moderate } \\
\text { Low } \\
\text { Very low }\end{array}$ & $\begin{array}{l}5 \\
4 \\
3 \\
2 \\
1\end{array}$ \\
\hline Distance to health facility & $26 \%$ & $\begin{array}{l}0-1,000 \mathrm{~m} \\
1,000-1,500 \mathrm{~m} \\
1,500-2,000 \mathrm{~m} \\
2,000-3,000 \mathrm{~m} \\
>3,000 \mathrm{~m}\end{array}$ & $\begin{array}{l}5 \\
4 \\
3 \\
2 \\
1\end{array}$ \\
\hline LULC* & $13 \%$ & $\begin{array}{l}\text { Water body } \\
\text { Wetlands } \\
\text { Forest } \\
\text { Agricultural land } \\
\text { Settlement } \\
\text { Scrubland }\end{array}$ & $\begin{array}{l}5 \\
5 \\
4 \\
3 \\
3 \\
2\end{array}$ \\
\hline
\end{tabular}

ability. In Shook's work, H represents a potentially damaging, natural phenomenon of a given magnitude threatening a given area, while $\mathrm{R}$ is the probability of $\mathrm{H}$ actually occurring within a specified period of time. E refers to the degree at which threatened ele-

\section{A}
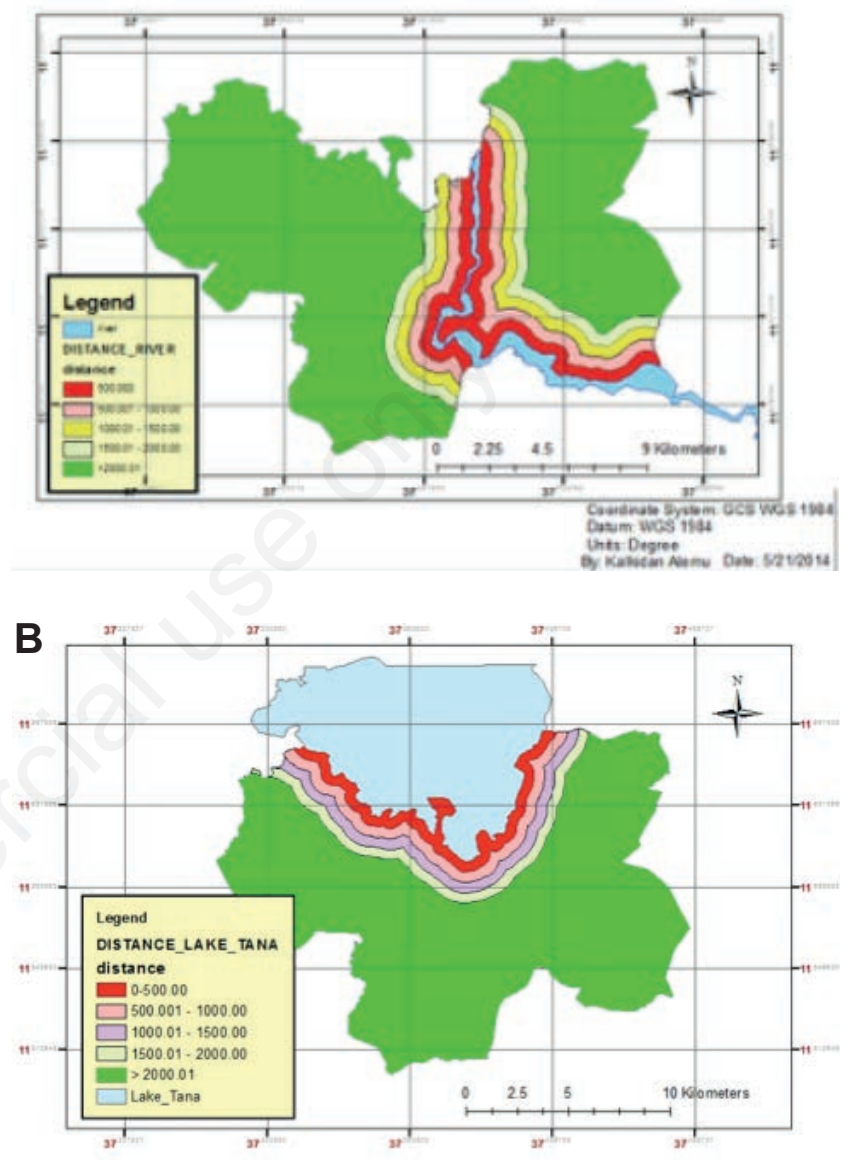

C

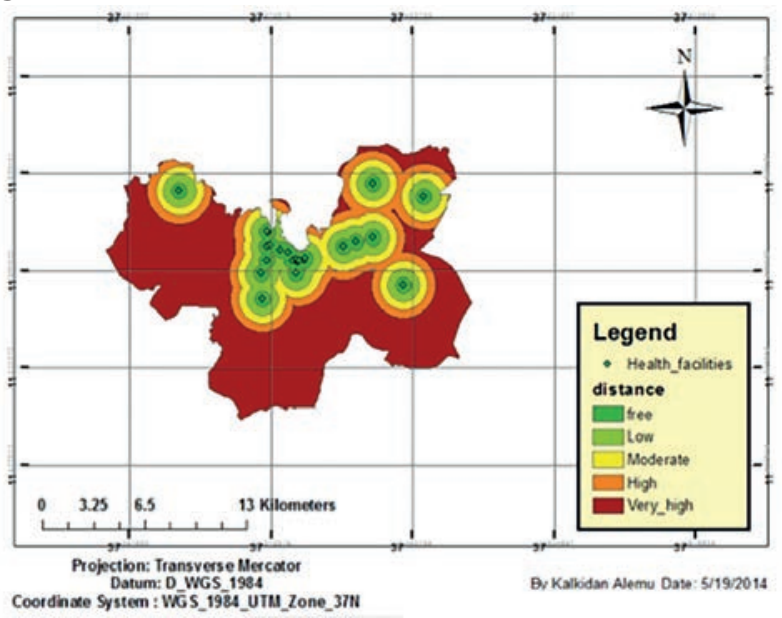

Figure 3. Proximity-related parameters in Bar Dar City. A) Proximity to River; B) Proximity to Lake Tana; C) Proximity to a health facility. 
ments, such as populations, property, economic activity, infrastructures, etc., would be directly affected should $\mathrm{H}$ actually occur (i.e. exposure), while $\mathrm{V}$ expresses E's degree of susceptibility to $\mathrm{H}$.

Shook's equation can also be utilized to estimate the risk of an epidemic occurring in a specified geographical area, where $\mathrm{H}$ would be the simultaneous presence of a case of malaria together with capable anopheline vectors ready to spread the infection into the wider population (E). The vulnerability can be quite complicated as it depends on the degree of immunity and general health of the population in question as well as its access to care and treatment. We mapped the malaria hazard using the ArcGIS raster calculator taking into account related previous work, national malaria guidelines, available reports $(\mathrm{FMoH}, 2008,2014)$ and the different environmental factors as these factors would modulate the core hazard (presence of a malaria case together with capable vectors). Special reference was paid to the temperature as it not only governs vector capability, but also the parasite's requirement inside the vector (Mordecai, 2013; Brhanie, 2016).

\section{Results}

As can be seen in Figure 5A, four areas with different levels of malaria hazard were found, i.e. very high (11.2\%); high (14.5\%); moderate $(63.3 \%)$; low $(6 \%)$; and one zone free of hazard $(5 \%)$. The three highest categories (moderate to high) in Bahir Dar City showed a higher hazard ( $89 \%$ of the whole area) than that reported from the Awassa Zuria Woreda in SNNPR which was estimated at $68 \%$ by Arega (2009) confirming that the malaria hazard of Bahir Dar City is considerably higher in spite of its higher altitude.

The map of malaria risk, i.e. the probability that malaria would spread in the population and the expected degree of loss due to malaria infection, was based on the equation formulated by Shook (1997) where E and H represented the population and the hazard, respectively, with $\mathrm{V}$ being the population's vulnerability based on proximity of health stations and LULC (Table 2). The outcome showed that most of the study area is at risk for malaria (Figure 5B), with a majority of the kebeles (small administrative units) subject to high or very high risk of malaria. Four areas with differ-

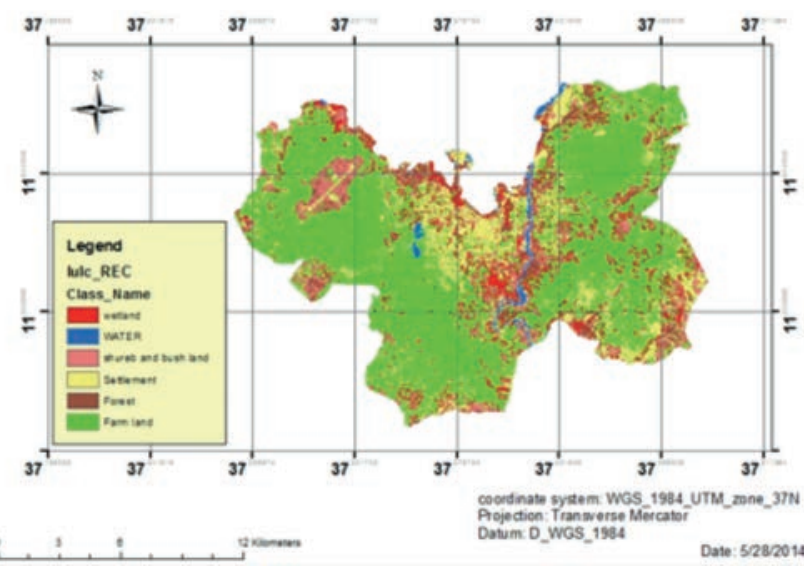

Figure 4. Land use and land cover. ent levels of malaria risk were found, i.e. very high (65\%); high $(15 \%)$; moderate $(8 \%)$; low $(5 \%)$; with only $2 \%$ of the area without risk (Figure 5B). Hence, it can be concluded that the great majority of Bahir Dar City (around $80 \% \mathrm{t}$ ) is at high to very high risk for malaria.

\section{Discussion}

As everywhere else, the malaria transmission intensity in Ethiopia, along with its temporal and spatial distribution, is determined by climatic conditions (Thomson et al., 1996; Abeku et al., 2003; Ceccato et al., 2005; Abiodun et al., 2016). A large part of the country is situated on a plateau, varying between 1500 and $2000 \mathrm{~m}$ above MSL, where the higher levels due to cooler temperatures experience malaria as occasional epidemics rather than through constant transmission (Bautista et al., 2006; Patz et al., 2008). The Ethiopian plateau forms the largest continuous highaltitude in Africa making altitude prominent among the variables affecting malaria transmission at these latitudes. Bahir Dar City at

A

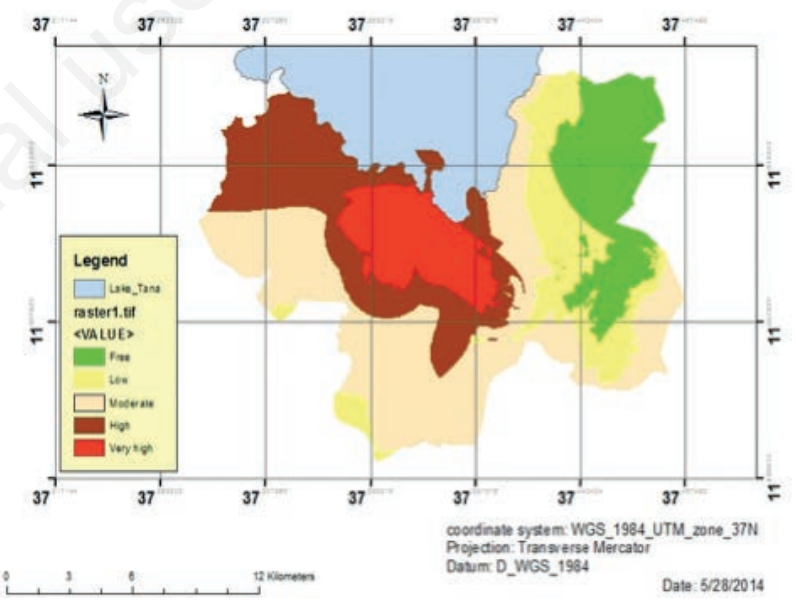

B

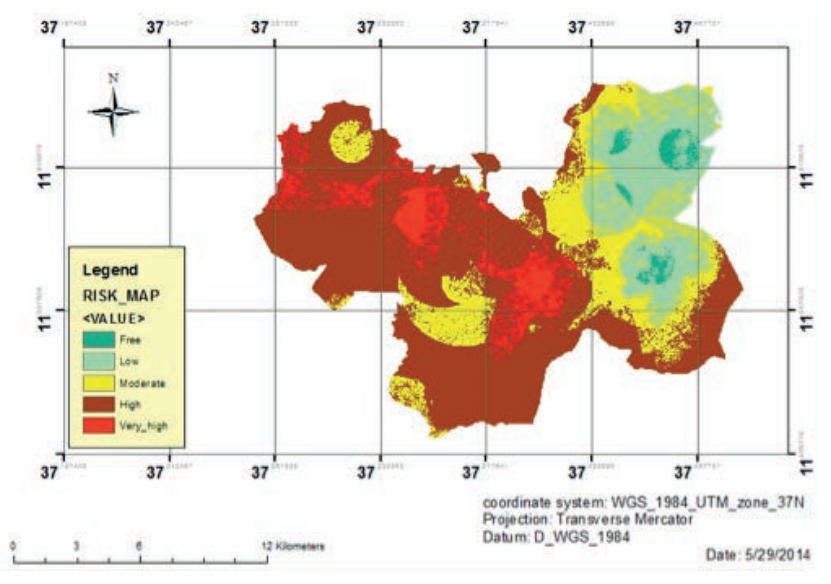

Figure 5. Variability of malaria risk in Bar Dar City. A) Malaria hazard map; B) Malaria risk map. 
1,800 $\mathrm{m}$ above MSL supports malaria transmission annually since the annual temperature there seldom sinks below $22^{\circ} \mathrm{C}$.

A rise in temperature enhances the survival chances of both Anopheles mosquitoes and malaria plasmodia and can thus accelerate transmission dynamics. However, an increase in temperatures does not mean an increase in malaria transmission if accompanied by a decrease in rainfall, since lack of water prevents development of the vector. At low temperatures, the vector needs to survive longer for the saprogenic cycle to take place, while temperatures above $30^{\circ} \mathrm{C}$ counteracts mosquito survival (Mordecai et al., 2013; Brhanie, 2016) (Table 1).

Rainfall creates favourable conditions for the mosquito malaria vectors (Rogerson, 2006; Omukunda et al., 2013; Abiodun et al., 2016). Although the mean annual rainfall in the study area is limited to about $800 \mathrm{~mm}$ annually, it is sufficient to support malaria transmission. Indeed, a study conducted in Boricha Woreda of Ethiopia at just a slightly lower altitude than Bahir Dar where the rains vary between 700 and $1200 \mathrm{~mm}$ per year has shown that this level of rainfall is sufficient for malaria transmission (Aster, 2010).

The study area contains strongly climbing slopes $\left(>20^{\circ}\right)$ which do not support anopheline vectors, but it also have many lower slope associated with very high $\left(0-7^{\circ}\right)$, high $\left(7-15^{\circ}\right)$, moderate $(15-$ $20^{\circ}$ ) of malaria hazard, respectively (Aster, 2010) (Figure 2). Such conditions accelerate chances for water stagnation creating waterlogged areas favourable for both mosquito breeding and mosquito survival (Thomson et al., 1999; Hailegiorgis et al., 2010).

Mosquitoes require motionless or slow-moving water to lay its eggs and to complete its life cycle. Rivers are therefore not conducive for this (Bekele et al., 2014), but the neighbourhood areas support mosquito breeding thanks to the increased humidity. Thus, proximity to water bodies is one of the factors associated with the malaria hazard. Another factor that also depends on proximity are those surrounding health facilities, which are not only important for treatment of patients, but also influence the prevalence of disease in the locality by the creation of awareness through its staff who knows the malaria situation in the immediately surrounding area, which translates into people living near health institutions are safer than those living further away (Aster, 2010, Hailegiorgis et al., 2010, Meron, 2010) (Figure 3).

Mosquito habitats differ according to the nature of local environment, e.g., with regard to vegetation. LULC classes with plantations have a strong association with malaria (Hailegiorgis et al., 2010), which was confirmed in the study area where a high incidence of malaria coincided with the prevalence of farms and vegetation lands. Special types of vegetation not only provide excellent breeding sites, but are also ideal sites for resting for adult mosquitoes as well as protection from adverse climatic conditions (Aster, 2010). Wetlands and agro-forestry areas accentuate the malaria hazard from that point of view (Haque, 2007). This study underlines the risk due to the fact that majority of the area is covered by farm lands and open vegetation (Figure 4).

Highlands should be recognized as areas of concern with respect to malaria and other vector-dependent infections. Recent evidence for an increase in the altitude of malaria distribution in Africa and South America (Siraj et al., 2014; Alelign and Dejene, 2016) confirms an earlier mathematical model identifying epidemic-prone regions in the African highlands (Lindsay and Martens, 1998). This implies that the malaria burden in the highlands of the tropics will grow if the global warming trend continues. Indeed, even a minor change in areas where malaria transmission is unstable could precipitate serious epidemics.

\section{Conclusions}

Malaria is a disease with high mortality that causes much suffering in the world. Various variables govern the level of risk with respect to this disease and GIS provide the necessary technology for identifying and combining these different variables, while RS plays the important role of providing the necessary environmental information. Planners and decision-makers should use these technologies to generate their information for further decisions. The malaria risk map is essential for this work and should contribute to the establishment of reliable early warning systems.

\section{References}

Abeku TA, van Oortmarssen GJ, Borsboom G, de Vlas SJ, Habbema JD, 2003. Spatial and temporal variations of malaria epidemic risk in Ethiopia: factors involved and implications. Acta Trop 87:331-40.

Abiodun GJ, Maharaj R, Witbooi P, Okosun KO, 2016. Modelling the influence of temperature and rainfall on the population dynamics of Anopheles arabiensis. Malar J 15:364.

Alemayehu L, 2011. GIS and remote sensing based malaria risk mapping in Fentale Woreda, East Shoa Zone, Ethiopia. Science College, Addis Ababa University, Ethiopia.

Alelign A, Dejene T, 2016. Current status of malaria in Ethiopia: Evaluation of the burden, factors for transmission and prevention methods. Acta Parasitol Glob 7:1-6.

Amare S, Kameswara R, 2011. Hydrological dynamics and human impact on ecosystems of Lake Tana, Norhwestern Ethiopia. Ethiopian J Environ Study Manag 4:56-74.

Amenu D, 2014. Prevalence of malaria among patients visiting Nekemte Hospital. J Med Microb Diagn 3:137.

Arega D, 2009. Vulnerability analysis and and malaria risk mapping i Awassa and Vonogenet woredas. MSc thesis. Addis Ababa University, Ethiopia.

Ashenafi M, 2003. Design and water management of irrigation systems to control breeding of anopheles mosquitoes. Case study: Hara irrigation project, Arba Minch, Ethiopia. MSc thesis. Wageningen, NL: Wageningen University; pp 88.

Aster T, 2010. GIS and remote sensing based assessment of malaria risk mapping for Boricha Woreda, Ethiopia. MSc thesis. Addis Ababa University, Ethiopia.

Bautista CT, Chan AS, Ryan JR, Calampa C, Roper MH, Hightower AW, Magill AJ, 2006. Epidemiology and spatial analysis of malaria in the Northern Peruvian Amazon. Am J Trop Med Hyg 75:1216-22.

Bekele D, Petros B, Tekie H, Asfaw Z, 2014. Larvicidal and adulticidal effects of extracts from some indigenous plants against the malaria vector, Anopheles arabiensis (Diptera: Culicidae) in Ethiopia. J Biofertil Biopestici 5:144.

Brhanie TW, 2016. The role of temperature for malaria transmission in Gongi Kolela District, Amhara Regional State, North West Ethiopia. Epidemiology (Sunnyvale) 6:281.

Ceccato P, Connor SJ, Jeanne I, Thomson MC, 2005. Application of geographical information systems and remote sensing technologies for assessing and monitoring malaria risk. Parassitologia 47:81-96.

Clennon JA, Kamanga A, Musapa M, Shiff C, Glass GE, 2010. Identifying malaria vector breeding habitats with remote sens- 
ing data and terrain-based landscape indices in Zambia. Int $\mathbf{J}$ Health Geogr 9:58.

Cooke BM, Mohandas N, Coppel RL, 2001The malaria-infected red blood cell: structural and functional changes. Adv Parasitol 50:1-86.

Dessalegne E, Suryabhagavan KV, Balakrishnan M, 2016. Malaria-risk assessment using geographical information system and remote sensing in Mecha district, West Gojjam, Ethiopia. J Geomat 10:55-64.

Dhiman RC, Pahwa S, Dash AP, 2008. Climate change and malaria in India: interplay between temperature and mosquitoes. Regional Health Forum, WHO 12:27-31.

Endo N, Eltahir EAB, 2018. Modelling and observing the role of wind in Anopheles population dynamics around a reservoir. Malar J 17:48.

FMoH, 2008. Ethiopia national malaria indicator survey 2007, Federal Ministry of Health, Addis Ababa, Ethiopia.

$\mathrm{FMoH}, 2009$. National strategic plan for malaria prevention, control and elimination in Ethiopia 2010-2015. Federal Ministry of Health, Addis Ababa, Ethiopia.

FMoH, 2014. Annual report, Federal Ministry of Health, Addis Ababa, Ethiopia.

Fontaine RE, Najjar AE, Prince JS, 1961. The 1958 malaria epidemic in Ethiopia. Am J Trop Med Hyg 10:795-803.

Guthmann JP, Llanos-Cuentas A, Palacios A, Hall AJ, 2002. Environmental factors as determinants of malaria risk. A descriptive study on the northern coast of Peru. Trop Med Int Health7:518-25.

Hailegiorgis B, Gima S, Melaku Z, Teshi T, Demeke L, Gebresellasie S.2010. Laboratory malaria diagnostic capacity in health facilities in five administrative zones of Oromia Regional State, Ethiopia. Trop Med Int Health 15:1449-57.

Haque U, 2007. Mapping malaria vector habitats in the dry seasons in Bangladesh using spot image. MSc thesis. TRITA-GIT EX 07-009. Stockholm, Sweden. Available from: https://pdfs.semanticscholar.org/f7e3/43c6fe52a3de8c71 edba2 82ecae314f3e001.pdf

Jima D, Getachew A, Bilak H, Steketee RW, Emerson PM, Graves PM, Gebre T, Reithinger R, Hwang J, 2010. Ethiopia malaria indicator survey working group. Malaria indicator survey 2007, Ethiopia: coverage and use of major malaria prevention and control interventions. Malar J 24:58.

Lindsay SW, Martens WJ, 1998. Malaria in the African highlands: past, present and future. Bull World Health Organ 76:33-45.

Meron M, 2010. Web GIS in decision support to control malaria, case study in Tiro Afeta Woreda, Oromia Region, Ethiopia. MSc thesis. Addis Ababa University, Ethiopia.

Mordecai EA, Paaijmans KP, Johnson LR, Balzer C, Ben-Horin T, de Moor E, McNally A, Pawar S, Ryan SJ, Smith TC, Lafferty $\mathrm{KD}, 2013$. Optimal temperature for malaria transmission is dramatically lower than previously predicted. Ecol Lett 16:2230.

Omukunda E1, Githeko A, Ndong'a MF, Mushinzimana E, Atieli $\mathrm{H}$, Wamae P, 2013. Malaria vector population dynamics in highland and lowland regions of western Kenya. J Vector Borne Dis 50:85-92.

Patz J, Campbell Lendrum D, Gibbs H, Woodruff R, 2008. Health impact assessment of global climate change: Expanding on comparative risk assessment approaches for policy making. AnnRev Pub Health 29:27-39.

Rogerson S, 2006. What is the relationship between haptoglobin, malaria, and anaemia? PLoS Med 3:e200.

Saaty TL, 1980. The analytic hierarchy process. New York, NY: McGraw Hill; pp 325.

Siraj AS, Santos-Vega M, Bouma MJ, Yadeta D, Ruiz Carrascal D, Pascual M, 2014. Altitudinal changes in malaria incidence in highlands of Ethiopia and Colombia. Science 343:1154-8.

Shook G, 1997. An assessment of disaster risk and its management in Thailand. Disasters 21:77-88.

Thomas CJ, Cross DE, Bøgh C, 2013. Landscape movements of Anopheles gambiae malaria vector mosquitoes in rural Gambia. PLoS One 8:e68679.

Thomson, MC, Connor SJ, Milligan P, Flasse P, 1996. The ecology of malaria as seen from Earth-observation satellites. Ann Trop Med Parasitol 90:243-64.

WHO, 2017. Malaria fact sheet.

Available from: http://www.who.int/mediacentre/ factsheets/fs094/ en/ Accessed: February 2018. 